\title{
Classroom Conflicts and Effective Resolution Strategies
}

\author{
Shazia Mansoori \\ Department of Education, Aligarh Muslim University, Aligarh, Uttar Pradesh, India \\ Corresponding author: shazia.ed@amu.ac.in
}

Received: 17 July, 2019

Revised: 25 Sept., 2019

Accepted: 27 Nov., 2019

\begin{abstract}
Conflicts are indispensable part of life of every individual in this world. Whether it is related to oneself or involving other people, conflicts occur on a daily basis. We cannot think of a world free from conflicts. Conflicts do not always create disputes but can also prove beneficial for the conflicting parties to grow in positive manner. In classrooms, we usually encounter conflicts of various kinds, be it intrapersonal, interpersonal, intragroup and intergroup. The key factor is to analyse the conflicts systematically, beginning from the root causes to the main problem and finally to effects which arise as a result of these conflicts. There are innumerous causes and factors which may conflicts in the learning environment. The analysis of any kind of conflict requires resolution strategies which most appropriately deal with the conflicting situation. The resloution strategies in this paper are discussed with reference to classroom conflicts and how a teacher can best utilise these strategies to build a peaceful classroom. Teacher's skills and styles for dealing with conflicts are also discussed. A motivating, collaborative and peaceful learning environment is created when the conflicts are effectively dealt and resolved.
\end{abstract}

Keywords: Classroom conflicts, Types of conflicts, Conflict- Resolution strategies, Skills of teacher

In everyday life, we come across situations where we are torn apart between choices or options. It becomes difficult to decide what to choose. The right decision involves overcoming the conflicting situation in an analytical and logical manner, keeping in mind all other factors which can influence the situation. "According to Denisi and Griffin (2005), conflict is a process resulting in the perceptions of two parties that are working in opposition to each other in ways that result in feelings of discomfort and/or animosity" ${ }^{[1]}$. There are instances where opinions of different people clash and thus conflicting situations may arise. Individuals with varied thoughts, ideas, perceptions, views, etc. may think differently and work in their own respective manner. Such differences may lead to non-acceptance, intolerance, arguments, etc. at times among the people. However, this is not true always. The differences may also give rise to better understanding of each others' opinions, mingling of ideas, constructive criticism and collaborative work. Thus, it can be seen that conflicts are not always bad, but the outcomes determine whether they are positive or negative. Conflicts are always there. They do not cease to exist. Conflicts can be defined as "natural disagreement resulting from individuals or groups that differ in belief, attitudes, values or needs". This implies that it is very natural

How to cite this article: Mansoori, S. (2019). Classroom Conflicts and Effective Resolution Strategies. Int. J. Peace, Edu. and Deve., 7(02): 129 134. 
for conflicts to occur and disengage people with others and even with oneself, but important point is that these conflicts need to be addressed on time to be resolved otherwise these conflicts may create disturbances within self and with others. Conflict is inevitable between administrators, teachers and students at schools where differences in culture, personality, values, beliefs, attitudes, needs, preferences, goals, interests and power come together. "Conflict is not a problem to be avoided but a process which leads to personal and social growth". A healthy outlook towards conflict is viewing it as an opportunity for growth and understanding. Conflicts can have positive value; if handled constructively:

$\odot$ "help us learn new and better ways to respond to problems;

$\odot$ help us build better and more lasting relationships;

$\odot$ help us learn more about ourselves and others;

$\odot$ lead to stronger group identity;

$\odot$ lead to a stronger sense of community;

$\odot$ lead to better communication" ${ }^{2]}$.

In the process of conflict, individuals who are involved fail to realise that they share much common ground, shared interests, but each one wants "things done their way". It is important that in classrooms, when such coflicting situations arise, the teacher needs to act as a collaborator or mediator to help the disagreed parties reach to an agreement, a middle path maybe. Conflicts occur only when incompatibility takes place, so in any case since the different perceptions can't be transformed, efforts to minimise the negative aspects should be taken. Examples of classroom conflicts generally observed are name calling, pushing/ shoving/ bullying/ spreading rumours, teasing, accusing, interrupting or even generalising. These act as starters for conflicts in schools. Even among the teachers, teacher- prinicpal, conflicts can arise at several places and times.

\section{Types of Conflicts}

The conflicts which arise in classrooms and elsewhere canbe caegorised into different types based on the number of individuals involved and the nature of interaction taking place. It's important to know and undesrtand the various types of conflicts as it will help in solving the conflicts in a more appropriate manner.

1. Intrapersonal conflicts- When we are caught between two choices that we have to make for ourselves, this is a kind of conflict which is with the self. Such type of conflict is known as Intrapersonal conflict. 'Intra' meaning 'within', implies making decisions about personal goals, aspirations, timeutilization, methods of teaching, selection of optional subjects, etc. For example: Student's conflict with the self to choose optional subjects, teacher's conflict with the self to decide methodology of teaching, etc. Intrapersonal conflicts occur when we are undecided between two alternatives, and both may seem attractive or unattractive. There are sub- types of intrapersonal conflicts-

(a) Approach-approach conflict: In this type of conflict situation, you have choices which all seem attractive to you. It becomes difficult to pick the most appropriate accordingly. The alternatives, whichever picked and chosen, will benefit the individual, however, one has to decide to choose one alternative out of those available. Once the choice is made, the stress decreases and conflict is resolved. For example: If there are two activities in classrooms in which you are equally interested but have to choose only one class activity in which you can participate, then you are dwelling in approachapproach conflict.

(b) Approach-avoidance conflict:A situation in which the available alternatives have both attractive and unattractive aspects. The individual finds it very difficult to overcome the stressful conditions in this type of conflict. The path taken will again depend on the balanced justification of his/ her decision. The individual is both attracted and repelled by the choices. The same choice/ goal will have aspects which are attractive to you and also certain aspects of the same goal which are disliked by you. Example: A student wants to study a course optional paper he likes but finds out that the class timings of the paper clash with his daily sports activity. In 
this case, the paper seems attractive because he /she will enjoy studying it but the timings of class are disliked by him/ her. Usually approach- avoidance conflicts involve only one goal.

(c) Avoidance-avoidance conflict: A situation in which the individual is caught between alternatives which are equally unattractive or undesirable. The situations are all stressful and unpleasant. However, conflict is when the person has to choose among these unwanted alternatives. For example: A student remaining home to avoid class test will have to clean the garage (without any help which is too tedious)! So, in both siuations the child is not happy but has to decide among these undesirable tasks. However, the individual tries to remain in stable equilibrium in this type of conflict, moving towards one alternative creates a stronger tendency to avoid it.

2. Interpersonal Conflicts: These types of conflicts arise when different individuals with different perceptions, needs, understanding, goals, attitudes, beliefs, values, etc. interact and incompatibility is seen. They occur between two or more individuals. They can be fights, arguments, or differences of opinion.These interpersonal conflicts occur every now and then in the society, they are unavoidable, repetitive and continue over time. These conflicts include policy conflicts, ego conflicts, value conflicts, misunderstanding, frustration, stress, etc. Interpersonal conflicts among people can cause deterioration/ harm of one person, on an individual basis, and detrimental effects can be seen in the orgainsation as a whole. Example: From a simple interpersonal conflict in which two students want to play guitar (only one available) in music class, to a complex interpersonal conflict where-suppose a teacher $X$ has been a good performer and liked by students, however, since last few days he/ she is not performing well in the class. Others who initially did not like the appreciation which the teacher X held, now confront him/her with criticism and negative remarks to the extent that principal has to intervene and issue a showcause notice to teacher $X$ for non- performance. Resolving each of the interpersonal conflict is important for smooth functioning of the system or organisation. Each interpersonal conflicts seem different in different contexts, the sole purpose in each is to understand the problem in hand, analyse the underlying causes and reasons in each situation and preparing the ground to minimise the effects of such conflicts.

3. Intra-group conflicts: These conflicts occur between individuak members of the same group or team. These arise because of individual differences and thus may impact team work/ group work/ or any other type of collaborative activity. This type of conflict is difficult to understand since it's difficult to comprehend the concept of 'group' in a large group say classroom or school. Once the members belonging to a group are identified, it becomes easier to understand 'intra- group conflicts'. Three types of intra- group conflicts have been identified- (a) taskrelated conflicts- occurs as disagreements beacuse of different opinions, ideas, views, etc. for completing a task/ activity, (b) process or procedure- related conflicts- occurs when there are disagreements related to assigning responsibilities, who should do what, commitmet, etc. for completion of the task/ activity and (c) relationship or personalityrelated emotional conflicts- occurs when negative interpersonal feelings (based on gender, religion, age, background, etc.) are present among the members towards one another. Task related conflicts help in collaborative work but the other two types generate negative impact. Examples of intra- group conflicts- Students given the chance to decide whether the farewell function will be conducted inside school or in a restuarant.

4. Inter-group conflicts: These conflicts occur when two or more groups disagree with each other on some goal, idea, perception, etc. These occur between groups, regardless of the size of the groups (classes, teams, communities, nations), as long as they are more or less of equal size. It takes place when a misunderstanding arises among different teams within an organization. This may occur between teachers and students (vertical conflicts), or among different students groups (horizontal conflicts). Each group is defined by certain characteristics different from the other group. Competition between the groups is usually responsible for this type of conflict. Example: 
Students in a class are distributed into teams and asked to participate in a competition, thus each team trying to win, sports teams competing over the right to use a particular athletic field, etc.

\section{Analysis of Conflicts}

The sources of conflicts are varied according to the type of conflict which is being faced. It's important always to identify the causes or sources of conflicts so as to plan better for resolution of conflicts. The usual reason in any kind of conflict is the difference in perception of individuals. One major categorization gives 3 major sources of conflictsResources, psychological needs, and values. Subdividing these sources of conflicts into:

1. Individual's social and cultural differences, values, needs

2. Varying attitudes and behaviour towards a particular goal, competition,

3. Utilization of resources, to gain power,

4. Relationships

5. Making assumptions

6. Intolerance

7. Lack of communication, sempathy.

Cannie, Sasse and CFCS (2002) affirm that there are some common factors which cause conflict in relationships, which are:

(a) "Situations or circumstances in which people find themselves,

(b) Personality of the individual or people, and

(c) The urge or desire for power" ${ }^{\prime[3]}$.

Fisher and Ury (1981) have outlined the following as some of the common causes of conflict in a workplace $^{[3]}$ -

(i) Unclear definition of responsibility - there will be numerous occasions for conflict to arise over decisions made or actions taken in disputed territory.

(ii) Limited resources - time, money, space, materials, supplies, and equipment are all valuable resources. Competition for any of these resources can inevitably lead to interpersonal and inter-departmental conflict.

(iii) Conflict of interest-According to Microsoft
Encarta Tool (2007), conflict of interest is a situation in which someone in position of trust, such as a lawyer, a politician, or an executive or a director of a corporation has competing professional or personal interests. Such competing interest can make it difficult to fulfill his or her duties impartially ${ }^{[4]}$.

At schools, conflicts may be experienced in many issues such as:

$\odot$ "Lack of communication,

$\odot$ Distribution of work among personnel,

$\odot$ Financial resources,

$\odot$ In and out of class teaching activities

$\odot$ Practices, rewards, punishment, assessment practices,

$\odot$ Use of power-authority,

$\odot$ Being late for class,

$\odot$ Political views,

$\odot$ Negative personal attitudes,

$\odot$ Scoring system,

$\odot$ Issues regarding the legislation,

$\odot$ Student behaviors, dress code,

$\odot$ Distribution of resources"(Karip, 2000) ${ }^{[5]}$.

Each source or cause of conflict needs to be studied thoroughly before trying to resolve them. Better resolution strategies can be used once we become aware of the causes and underlying root problems due to which conflicts have arisen. A diagrammatic representation shows ${ }^{[6,7]}-$

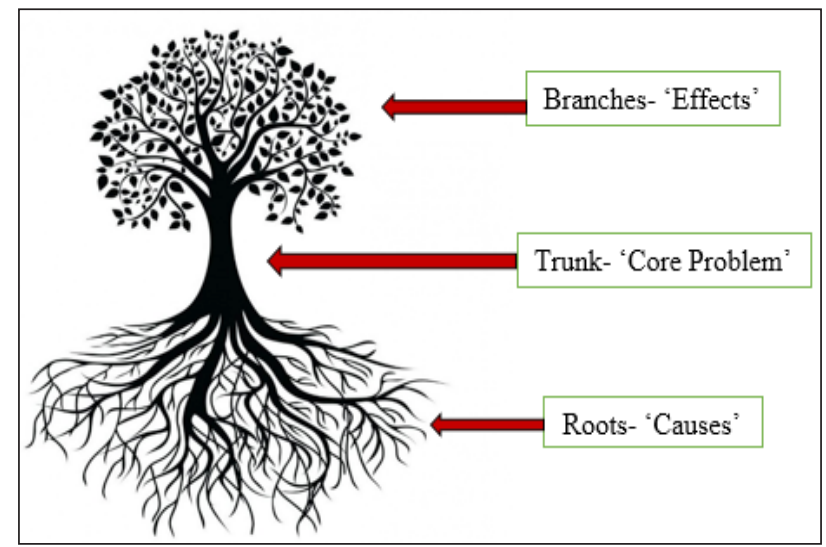

Fig. 1: Conflict tree analysis

(Adapted from Source: Simon Fisher et al. (2000)) 
The conflict tree analysis describes the causes or sources of conflicts as 'roots', the main problem underlying the conflict as 'trunk/ body' and the positive and negative effects/ consequences of the conflict as 'branches' of a tree. When a conflict is encountered, the root causes are left unnoticed and the whole focus remains on the core problem of conflict. It's necessary to find out the root causes otherwise conflicts may arise in new forms again and again. We need to identify the underlying 'needs' that have led to conflicts in the first place. Apart from the root causes, the attitudes and behaviour of the conflicting individuals, and the situation are also important elements to be studied. This practical and thorough analysis of conflicts will reveal understanding from various perspectives and thereafter appropriate resolution of conflicts. Through conflict analysis, we are able to (i) understand the background and history of the situation, (ii) current events that precipitated the conflict, (iii) all the relevant groups and individuals involved, not just the main or obvious ones, (iv) understand the perspectives of all the groups and individuals and know more about how they relate to each other, $(\mathrm{v})$ identify factors and trends that underpin conflicts, and (vi) learn from failures as well as success ${ }^{[7]}$.

\section{Resolving Conflicts}

The aforementioned conflicts, types of conflicts and conflicts analysis have been dealt effectively but mere understanding of conflicts is not sufficient, one has to devise ways, skills, strategies to resolve conflicting situations in best possible manner. Management of conflict is important because it minimizes negative effects and promotes positive outcomes. In educational institutions, conflicts should be resolved and managed in time, so to achieve the goal of learning. Constructively dealing with conflicts is a skill acquired by the teachers and other stakeholders of learning. "Assumptions about conflict, which facilitate the process of conflict resolution:

(1) In a conflict situation, we must try to fully understand other's frame of reference.

(2) The status of the person should not come in the way.
(3) Conflict should be considered as a mutual problem to be solved cooperatively rather than as a win lose proposition.

(4) It is better to choose a mutually acceptable time to sit down and work on resolving the conflict and not to tackle the conflict as and when it arises,

(5) It is better to communicate the flexibility and willingness to modify one's position while dealing with conflict" ${ }^{[7]}$.

There can be different styles and skills developed and acquired by educators to avoid undesirable behaviours and situations in the classrooms. These are discussed below:

\section{Teacher's Skills to deal with conflicts}

(a) Communication- Good listening skills

(b) Active listening- Paraphrasing, Physical attention, Reflecting, Clarifying Questions

(c) Dialogue- creation of a psychological and physical safe place, whole exercise is to learn from each other, to discover each other, to inquire, explore and discover.

(d) Facilitation- Helping individuals and groups complete a task, solve a problem or come to an agreement to the mutual satisfaction of the people participating in the dialogue or discussion.

(e) Negotiation- Individuals with shared and opposed interests work out a settlement in order to come to an agreement, Separate the people from the problem, Communicate effectively, Focus on interests; not on a position, Generate multiple options, Commitments made during the process of negotiation should be realistic.

(f) Mediation- Provide a climate in which both parties can come together and open communication for facilitation.

2. Styles to deal with conflicts

(a) Avoidance style: Nervous about the consequences, avoid conflicts

(b) Accommodation style: Giving in easily, low concern for self, high concern for others

(c) Competing style: High concern for self, can do anything to win 
(d) Compromising: Willing to negotiate, Both the parties give up something so that both can have partial satisfaction or gain

(e) Collaboration style: Most constructive approach, encourages openness and trust, focus is on the idea.

\section{Conflict Resolution Strategies in Classrooms}

(a) Directly teach students the skills they need to work in partners or groups, including the importance of communicating needs, setting goals, and what to do if something goes wrong

(b) Encourage students to role-play situations that require empathy, communication, and problem-solving

(c) Help students see how their actions impact others, both positively and negatively, by including these observations in everyday conversation. Phrases such as, I feel confused when you..., I feel happy when we..., or we work best together when..., help students make this connection.

(d) Teach students your process for resolving classroom conflicts before issues come up. This way, students are prepared to take an active role in resolving their own problems.

(e) Remember that conflicts often arise from a combination of fear, anxiety, or frustration. Help students learn to recognize emotional triggers and manage them in healthy ways, such as with mindful activities, movement, or reflection ${ }^{[8]}$.

\section{CONCLUSION}

Conflicts involve those situations where the individuals are interdependent and they influence each other as a result of differences in achieving the desired goals. In educational institutions, conflicts may occur between head of the institution and the teacher, teachers- teacher, teacher and student, and students- students. Conflicts may result in hostile attitude, inappropriate behavior, lowers morale, hampers productivity and create misunderstandings. They may remain unchecked and unmanaged for a long period of time. However, unresolved conflicts are always harmful to the integrity and functioning of any educational institution. On the other hand, conflicts are also important when positive outcomes are needed, for e.g., conflicts helps in raising problems, identifies the different viewpoints, and may realise benefits from the differences. Different types of conflicts result in different positive and negative aspects, therefore they need to be deal accordingly. The understanding and resolution of conflicts in classrooms and elsewhere necessitates a deep analysis of the root causes, core problem, and resulting effects. The goal of conflict resolution is not just putting an end to the conflict but also aims to empower students to learn from their mistakes, solve their own problems, and contribute positively to the classroom community. Good interpersonal relationships are important for effective classroom teaching- learning process. Conflicts may offer both competitive and collaborative opportunities. The role of educators is important to handle conflicting situations by recognizing the problem, analysing the positive and negative outcomes, and then using conflict- resolution strategies in practical ways. Problem solving, and peer mediation training need to be constructively used for developing a peaceful classroom, in order to cultivate an atmosphere of mutual acceptance, tolerance, accommodation $\mathcal{E}$ understanding.

\section{REFERENCES}

1. Isabu, M.O. 2017. Causes and management of school related conflict. African Educational Research Journal, 5(2): 148- 151.

2. Anonymous. 2009. The Dynamics of Conflict. Freshman Seminar, The Johns Hopkins University. Retrieved from www.tdschools.org > 2011/12 > Unit-5-Lesson-1

3. Margaret Owusu - Mensah, 2007. Conflict in Primary School and its Effects on Teaching and Learning: A Case Study of Ejisu-Juaben District (Master's Dissertation). Kwame Nkrumah University of Science and Technology. Ashanti Region, Ghana.

4. Fisher, Y. and Ury, H. 1981. Management Issues in Elementary School Classroom. Arrow Books, London.

5. Süleyman Göksoy and Türkan Argon. 2016. Conflicts at Schools and Their Impact on Teachers. Journal of Education and Training Studies, 4(4): 197- 205.

6. Simon Fisher et al. 2000. Working with Conflict: Skills and Strategies for Action, New York: Zed Books \& Responding to Conflict, pp. 29.

7. Pant, D. and Gulati, S. 2010. Ways to Peace, Publication Department by the Secretary, National Council of Educational Research and Training, Sri Aurobindo Marg, New Delhi.

8. https://www.learnersedge.com/blog/resolving-conflictin-the-classroom 